\title{
MARBOWL: increasing the fun experience of shooting marbles
}

\author{
Jabe Piter Faber $\cdot$ Elise van den Hoven
}

Received: 10 October 2009/Accepted: 27 January 2010/Published online: 18 June 2011

(c) The Author(s) 2011. This article is published with open access at Springerlink.com

\begin{abstract}
This paper focuses on the old school game of shooting marbles. We investigate which aspects of this tangible game make it popular and show how experienced fun can increase by elaborating such aspects through an iterative design process. A questionnaire and field study, tailored to the user group of primary school children aged 9-12 years old, revealed that aspects within areas of physical control, surface of the playground, opponent, and stakes of the game had the biggest influence on the fun experience of shooting marbles. A gameflow model and fun toolkit were used to improve the game in these respective areas. This resulted in a moving marble hole entitled Marbowl: a tangible marble game that augments existing game aspects such as timing, distance, surface, and other physical and environmental influences. A working prototype was field tested with 24 children at a primary school. Results show that different gameflow areas like concentration needed, playability, difficulty to win the game, and amount of challenge, increased in a positive way. Together these findings concluded that compared with the original marble game, children experienced a higher level of fun while playing with Marbowl.
\end{abstract}

Keywords Fun experience - Gameflow ·

Tangible interaction · Design for children · Social gaming · Open-ended play

\footnotetext{
J. P. Faber $(\bowtie) \cdot$ E. van den Hoven Industrial Design Department, Eindhoven University of Technology, P.O. Box 513, Den Dolech 2, 5600 MB Eindhoven, The Netherlands e-mail: jabe@jpfdesign.nl

E. van den Hoven

e-mail: e.v.d.hoven@tue.nl
}

\section{Introduction}

Shooting marbles is a game that has been played for centuries, dating back to the ancient Roman and Egyptian Empires. Every spring it is played on many schoolyards all over the world, with players competing against each other to win as many marbles as possible by shooting their marbles in a designated target or hole. With toy stores full of the latest inventions and children having more toys than time to play, we wondered what makes this old school game so popular.

The term old school game refers to physical games such as playing tag, hide and seek, hopscotch, and shooting marbles. All are games that have been played by our parents and grandparents on the schoolyard. Some of these games have been used for the development of new games, using several successful aspects of a game to create another popular game. E.g., the FlippoTM [11] hype that integrated a lot of elements of the marble game such as collecting items, winning items through competition, and trading items. More of these trends and hypes emerge on schoolyards every year but often seem to last only for short periods of time, while the old school games mentioned seem to outlive these hypes again and again. Because of its popularity and it being a physical and social active game, we chose to focus our study on the shooting marble game.

With the rise of the personal computer and game consoles, developments within the entertainment industry show an increase in digital toys. In order to encourage physical activity among children, new trends emerge, combining physical movement and interaction with such toys. Examples of such platforms are the Nintendo WiiTM, Nintendo DSTM, and the PlayStation2TM EyeToy PlayTM. The success of these platforms indicates the potential of such bodily interactions in digital games. We see 
existing physical games like bowling, tennis, and other physical games digitalized, yet controlled in a similar way to the actual game. However, most of these games still focus on or around a screen and thereby miss opportunities in areas like active physical play and room for playing in large groups. In order to address these opportunities, we focused on the integration of digital elements into a physical game, instead of looking for the integration of physical interaction within a digital game.

The integration of digital elements within physical games almost seems normal nowadays and existing game concepts often are improved by adding technology. For example, the Swinx [29], an outside game console which uses RFID and sound to play multiple traditional games; and SmartUs [25], an outdoor playground enriched with electronic game elements that can be combined to create a playful learning environment. However, such games are often rule based and do not stimulate open-ended play [7, 31], which can discourage both physical and social activity within a game. We aimed to design a physical game that integrates open-ended play while using the advantages of technology. We tried to pursue this by improving existing game aspects instead of creating new rules and boundaries.

This paper makes a contribution in the area of designing tangible games for children that integrate open-ended gameplay and stimulate physical and social interaction. By these implementations, we aim to increase the experienced fun, as described by Read et al. [23]. We discuss ways to increase the fun experience by analyzing current success factors and by redesigning game elements of the existing shooting marble game.

\section{Related work}

More than a decade ago Acuff et al. [1] started to study children as a special user group, after that, others like [8, $10,16]$, started looking at human-computer interaction with children for different purposes. Game design has been a central focus in many studies and over time expanded into many sub-genres such as computer games, physical games, tangible tabletop games, head-up games, and openended play. Read et al. [23] indicate that the experience of fun within games can be based upon the three dimensions of expectations, engagement, and endurability and be measured through tools like the Fun Toolkit [22]. Another approach is that of the concept of Flow [9], which implies that pleasure or enjoyment is based upon the areas of challenge, merging of action and awareness, clear goals and feedback, concentration, control, loss of self-consciousness, and transformation of time. Sweetser et al. [28] looked at the concept of flow within digital games and created a new model with eight areas to measure and improve the level of enjoyment. Their research compared two digital games by rating the games on the different criteria set per area. They showed that the success factors of a game can be derived from such an analysis. Although their gameflow theory focuses on digital games, the approach and expected results make this model seem appropriate for our research. In relation to our subject of shooting marbles, we therefore aimed to apply the gameflow model on a physical game instead of a digital game.

\subsection{Physical gaming}

Within the area of physical games for children, several new interactive concepts have been developed. Because of the renewed interest in physical interaction in play and the development of new technologies, new concepts emerge. For example; the Interactive Pathway [24], an open-ended playground that connects movement of a child to digital feedback in order to explore the integration of playgrounds in a digital era; FlashPoles [6], a game installation for the playground of tomorrow, focusing on increasing physical activity; and Playware [33], a playground made out of responsive physical building blocks that provide feedback on movement of players. These tangible games indicate a positive influence on the social and physical development of players and the experienced fun during the game. A new research area that is strongly connected to physical and outdoor games is that of Head-Up Games or HUG's [17, 26] which mainly focuses on supporting traditional ways of gameplay. HUG's are pervasive outdoor games that focus on gameplay without any display or PDA-styled interactions to stimulate social interaction.

Above-mentioned studies imply that the outdoor context of a game often influences the physical and social activity of the players in a positive way. The tangible interfaces used often support this interaction with and between multiple persons.

\subsection{Tangibles for children}

With the development of new physical interfaces, new complex behaviors can be computed. These behaviors have to be addressed in a usable and enjoyable way, especially when designing for children. TUI's like [4], empower these mappings from complex digital computations to simple physical interactions by looking at the abilities of human beings and the way they interact with physical objects in their environment [13]. Within the field of tangible interaction the topic of children is perhaps the only specific domain that is maturing enough to have resulted in domainspecific frameworks [18], the one most relevant to this paper is the CTI-framework by Antle [2]. The framework, consisting of the five dimensions of Space for Action, 
Fig. 1 The four phases of the study described in terms of their goals, methods, outcomes, and location of the sections in this paper that discuss the different phases

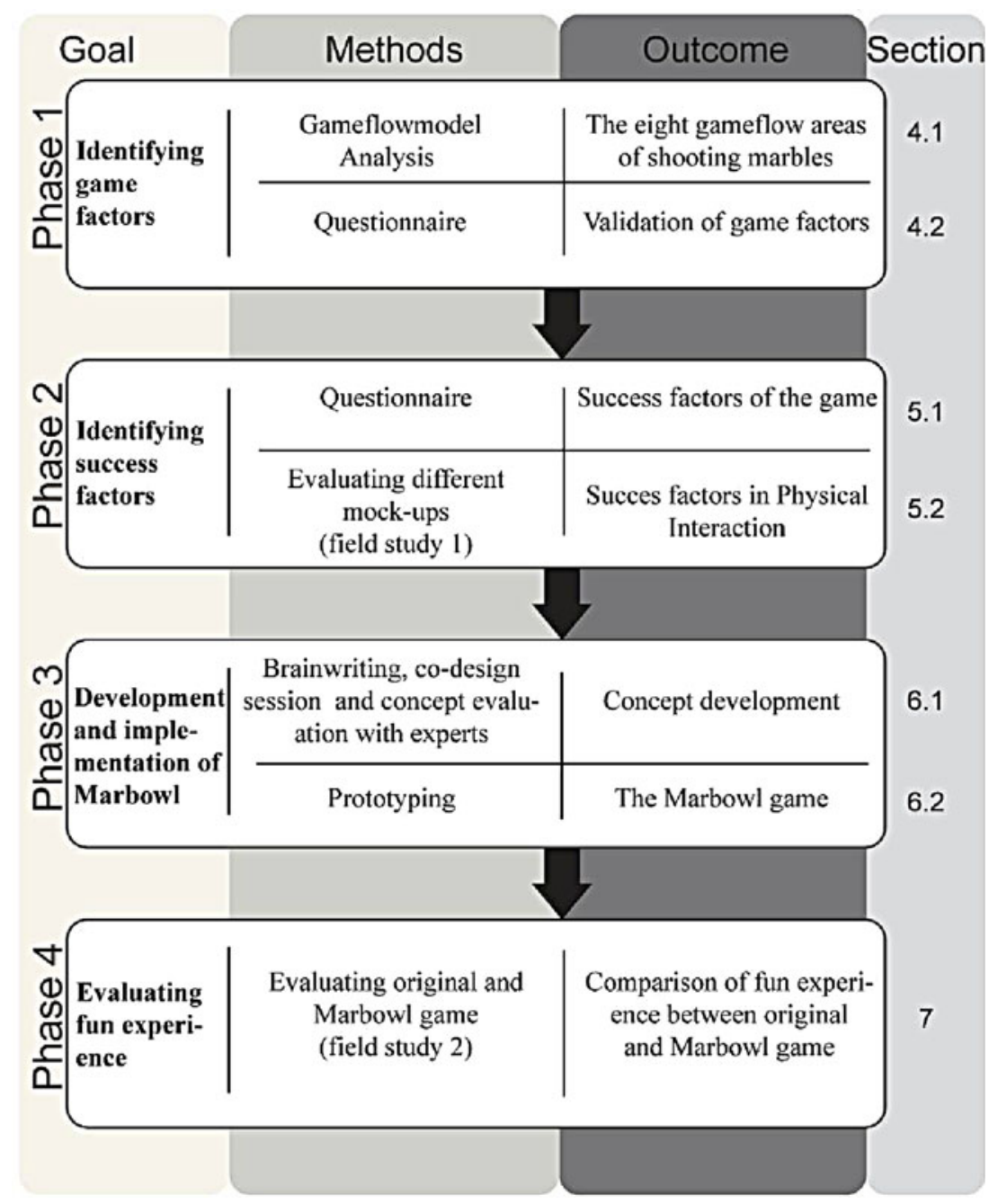

Perceptual Mappings, Behavioral Mappings, Semantic Mappings and Space for Friends, shows how we can utilize the benefits of tangible and spatial systems to stimulate cognitive development.

According to $[15,21]$, playing with tangibles increases excitement and collaboration and stimulates the child's development. This also increases the amount of engagement in learning activities. The work by Xie et al. [32], where traditional, graphical, and tangible interfaces are compared with each other, also validates that the use of tangible interaction increases the amount of fun as well as the effectiveness of the children's actions.

Where the aforementioned game consoles already move toward a more natural way of controlling screen-based games, many studies are done regarding tangible interactions in traditional games. Concepts like, Weathergods [3], a fusion of traditional board games and computer games on a tabletop screen; GranulatSynthese [5], a rear-projected tabletop screen where synthetic particles are used to create ambient and meditative audiovisuals; and the Tangible Jigsaw puzzle [32] that looks at engagement in interaction in comparison with graphical and physical user interfaces, show us that like physical gaming, new interaction methods stimulate experienced fun and social interaction within games.

\section{Paper overview}

To determine whether the fun experience of shooting marbles can be increased by applying the gameflow theory, the study included four distinct phases (see Fig. 1). We first defined the game factors of shooting marbles (Phase 1-Sect. 4) within the different areas of gameflow, then indicated which of these are the success factors by involving users (Phase 2-Sect. 5). The success factors were implemented into a new game concept (Phase 3-Sect. 6). Finally, a working prototype was used during a field study to evaluate the experienced fun of players while playing with the new and original game (Phase 4-Sect. 7). We end this paper with a Discussion (Sect. 8) and Conclusions (Sect. 9). 
Table 1 The eight areas of gameflow, with the main criteria set by Sweetser et al. [28], and the results of the analysis of the marble game

\begin{tabular}{|c|c|c|}
\hline $\begin{array}{l}\text { Gameflow } \\
\text { area }\end{array}$ & Criteria & Factors of shooting marbles \\
\hline Concentration & $\begin{array}{l}\text { Games should require concentration, and } \\
\text { the player should be able to concentrate } \\
\text { on the game }\end{array}$ & $\begin{array}{l}\text { The environment of the playground; the } \\
\text { surface of the playground; the beauty, shape, } \\
\text { and number of the marbles and the stakes } \\
\text { (value of the marbles) of the game }\end{array}$ \\
\hline Challenge & $\begin{array}{l}\text { Games should be sufficiently challenging } \\
\text { and match the player's skill level }\end{array}$ & $\begin{array}{l}\text { The difficulty of the opponent; addition of } \\
\text { rules; different playground surfaces; and } \\
\text { collecting different marbles }\end{array}$ \\
\hline Player skills & $\begin{array}{l}\text { Games must support player skill } \\
\text { development and mastery }\end{array}$ & $\begin{array}{l}\text { Developed by; watching other players play; } \\
\text { by playing; and by rewarding higher skills } \\
\text { when winning and damaging lower skills } \\
\text { when losing }\end{array}$ \\
\hline Control & $\begin{array}{l}\text { Players should feel a sense of control } \\
\text { over their actions in the game }\end{array}$ & $\begin{array}{l}\text { The direct physical interaction; the surface of } \\
\text { the playground; and the number and size of } \\
\text { the marble(s) }\end{array}$ \\
\hline Clear goals & $\begin{array}{l}\text { Games should provide the player with } \\
\text { clear goals at appropriate times }\end{array}$ & $\begin{array}{l}\text { Determined by the players agreement before } \\
\text { the game begins }\end{array}$ \\
\hline Feedback & $\begin{array}{l}\text { Players must receive appropriate } \\
\text { feedback at appropriate times }\end{array}$ & $\begin{array}{l}\text { Direct physical and visual feedback from } \\
\text { actions; number of marbles in the hole and } \\
\text { on the field notifies both players of } \\
\text { completion failure, progress, and goals }\end{array}$ \\
\hline Immersion & $\begin{array}{l}\text { Players should experience deep but } \\
\text { effortless involvement in the game }\end{array}$ & $\begin{array}{l}\text { The concentration needed during the game; } \\
\text { the amount of control; the level of social } \\
\text { interaction; and addressing different senses }\end{array}$ \\
\hline $\begin{array}{l}\text { Social } \\
\text { interaction }\end{array}$ & $\begin{array}{l}\text { Games should support and create } \\
\text { opportunities for social interaction }\end{array}$ & $\begin{array}{l}\text { The amount of players playing the game; } \\
\text { trading of marbles; finding new challenges; } \\
\text { and different communities }\end{array}$ \\
\hline
\end{tabular}

\section{Identifying game variables (Phase 1)}

Before we can determine success factors of the game, we have to know which factors form the game of shooting marbles. To retrieve these factors, the gameflow [28] method was applied by the authors to evaluate the game on eight different gameflow areas. Each area consists of different criteria (see Table 1, and for more detail [28]) that, after we analyzed the game, indicated the factors that form the foundation of the game. The derived factors were then validated by experts that rated the factors on a 5-point Likert scale, in accordance with [30]. This eventually indicated which factors influence each gameflow area the most and can be called success factors.

The group of experts consisted of 17 students from the Eindhoven University of Technology aged 21-25 years old, who were experienced marble players. They rated each factor from 1 (no influence) to 5 (high influence) and indicated whether there are other factors influencing each gameflow area. Experienced adult marble players were chosen to participate in this part of the study because of their ability to give a better explanation and reasoning for their rating than children [10]. E.g., participants were asked to rate in what level listed factors determine the challenge of the game, where the given factors were: difficulty of the opponent, addition of rules, different playground surfaces, and collecting different marbles. For each gameflow area, they were asked to indicate other factors that could influence the area. The results can be generalized to the current target group, because the mechanics of the game did not change in the last decades.

\subsection{The eight gameflow areas of shooting marbles}

We used the eight gameflow areas (see Table 1) to analyze the game of shooting marbles. The detailed sets of criteria, such as; Games should provide a lot of stimuli from different sources, games should provide stimuli that are worth attending to (concentration), players should receive immediate feedback on their actions (feedback), and games should support competition and cooperation between players (Social Interaction), can be found in [28]. The results of the analysis indicated different game factors such as the surface, opponent, and physical interaction that form each gameflow area.

\subsection{Validation of analysis}

Analyzing the ratings given by the experts indicated that the most important missing factors of our analysis regarded 
skill development, physical interaction, and goals of the game. Where the factor of "playing" in the area of Player Skill implies learning through play, respondents indicated that this could be more specific, like practicing alone or with a friend. The factor of physical interaction with the marbles was also indicated as missing but was filed under the gameflow areas of player skills, control, and feedback. The area of clear goals of the game was indicated as obsolete; many respondents mentioned that the goal of the game is clear and often basic knowledge for every player.

Together with the other game factors that came out of our own analysis, the ratings by the experts resulted in four factors that were indicated as most influencing and interesting to develop further:

- Stakes of the game

- Opponent

- Surface

- Physical Interaction

A high rating within the gameflow areas of concentration and immersion indicated the importance of the stakes of the game. The opponent is indicated as highly influential on the areas of challenge, goals, rules, and social interaction. The surface is rated as high in influencing the area of control, concentration, and challenge, and the physical interaction focuses on the areas of player skills, feedback, and control.

\section{Identifying success factors (Phase 2)}

\subsection{Success factors of the game}

To indicate how the four previously mentioned factors should be addressed within concept development, each factor was evaluated by the actual target group. Throughout Phase 2 and 4 of the study a primary school class of 24 children, aged 9-12 years old ( 8 girls and 16 boys), were participating in our evaluation studies. Using an entire class for both survey and field studies provided a natural setting for playing games during school breaks and at the same time, the teachers could provide assistance during these evaluations [20]. Earlier studies [14, 31] show that using the same user group throughout an entire study can have benefits regarding the attuning to the research topic and design directions. However, using the same respondents in multiple phases of the study can have a negative influence on the validity of the study done; therefore, the target group was only involved in generating valuable data on the game factors and success factors of shooting marbles and the evaluation of the final concept. By not involving the children in the actual design of the final concept, we tried to minimize desired answers given during the evaluation.
The class was asked to fill out a simple and understandable questionnaire that consisted of several multiplechoice questions, where the four factors mentioned in paragraph 4.2 were rated on importance, and several open questions to indicate why they gave that rating. E.g., the children were asked to indicate how important it is for them to win the game, rating it on a scale of; most important, very important, important, not very important, or not important at all.

The first question focused on demographic data and information about regularity and affinity of playing with marbles. Four following sections specifically looked at the experiences, preferences, and desires of the user regarding the four factors. Within $45 \mathrm{~min}$, the children had to finish the questionnaire where after they were given a reward for their efforts.

After analyzing the results, the following conclusions could be made:

The stakes: Turned out to be less important than our expectations based on the gameflow analysis in Phase 1. The majority rated the stakes as not or not at all important. The qualitative results of the open questions indicated that the beauty of marbles matters most when judging the value of marbles. The stakes were indicated as influential on the players' behavior, though the amount of influence and the behavioral reaction is likely to be very personal because of the diversity of reasons given.

The opponent: Most children indicated that it is not the opponents' skill that influences the fun experience but the social behavior of the opponent. Out of the options of playing against someone who is better, worse, or equally good and a fourth option of "doesn't matter", 17 of the 24 children indicated that it did not matter whether the opponent was better or worse at shooting marbles. Almost every respondent indicated that it is important to play against friends or players they know. In addition, an equal amount of player skill was preferred to keep the game challenging.

The surface: Given the options of playing on sand or tiles, 16 of the 24 children indicated to rather play on a tiled surface. As an improvement, the majority indicated that they would like to see (integrated) obstacles that make the game more challenging and fun. The ability to use your surroundings and surface to influence the game are the most important and interesting aspects of the surface.

The physical interaction: Children indicated that using fingers to shoot marbles provides direct feedback, and the amount of force applied on the marble can be accurately controlled. Aiding the player in shooting the marble is experienced as spoiling the game. Finally, the children indicated that, though the feeling of having control should remain, the difficulty of reaching the target may be increased to improve the game. 
Looking at these results, we elicited the following success factors of the shooting marble game:

- The stakes of the of the game are variable

- The game stimulates social interaction

- The game leaves room for individual manipulation of its environment

- The game integrates direct physical control and direct feedback on actions

- The game leaves room for personal skill development

\subsection{Success factors in physical interaction}

Most of aforementioned success factors could be addressed by developing the area of Physical Interaction. Because previous results indicated a preference for developing this factor and time did not permit us to develop all four, we chose to continue our research in this specific area. In order to study the opportunities for developing the physical interaction of the game, we came up with four different game variants (see Fig. 2). They explore in what way the interaction can be improved to increase the experienced fun. A setup was made where the amount of physical control and feedback on aiming and shooting the marble increased, decreased, and remained the same.

The 2-h field study was performed on the schoolyard during school breaks, which is a familiar context for shooting marbles.

The setting consisted of one marble hole per group and five marbles per child. A child played with all the marbles on the field, always toward the hole and won the game when he or she shot the last marble into the hole. The game started with throwing all marbles toward the hole, the player whose marble was closest to or in the hole, shot the first marble. Shooting a marble in the hole allowed the player to shoot again. When missing the hole, the player's turn ended and shifted to the next player. This continued until the last marble was scored.

The four game variants played are:
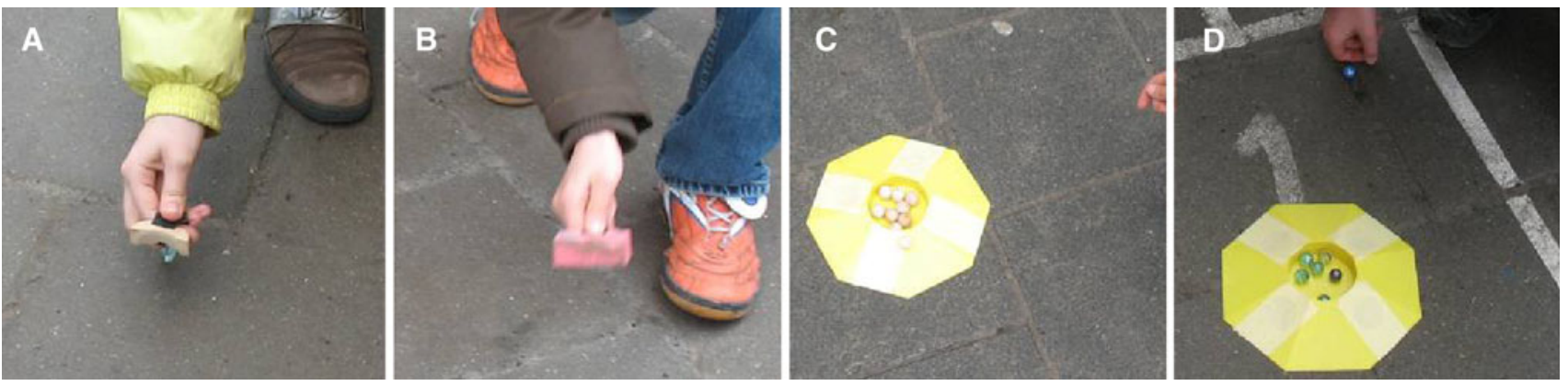

Fig. 2 The four different game variants: Wooden finger variant (a), Sponge finger variant (b), Magnet Marble variant (c), and Regular variant $(\mathbf{d})$ 
Table 2 Ranking of the four different game variants by the children

\begin{tabular}{lll}
\hline & Highest experienced fun & Highest difficulty \\
\hline 1 & Magnet marble variant & Sponge finger variant \\
2 & Regular game variant & Wooden finger variant \\
3 & Wooden finger variant & Magnet marble variant \\
4 & Sponge finger variant & Regular game variant \\
\hline
\end{tabular}

Number 1 is the highest score; number 4 the lowest

- Aiding children in gaining control over the marble is experienced as boring and results into a lesser fun experience.

- Adding an extra element without changing the physical interaction is experienced as more positive.

\section{Development and implementation (Phase 3)}

\subsection{Concept development}

The results discussed in the previous section were further developed into a final design through a braindrawing and co-design session of approximately $1.5 \mathrm{~h}$ with six Industrial Design students (4 male, 2 female). Each participant received a form on which they drew four different marble game concepts, using the conclusions of previous phases. They then passed the form to their neighbor who drew four new concepts based on the previous concepts on the form. Eventually, every form contained 24 different concepts which were evaluated by the original owner of the form, from which they chose the two most preferred concepts. The final 12 concepts were discussed, evaluated, and rated by a "Couple Comparison" [27], which eventually led to five different concepts for further development, as described below (Fig. 3).

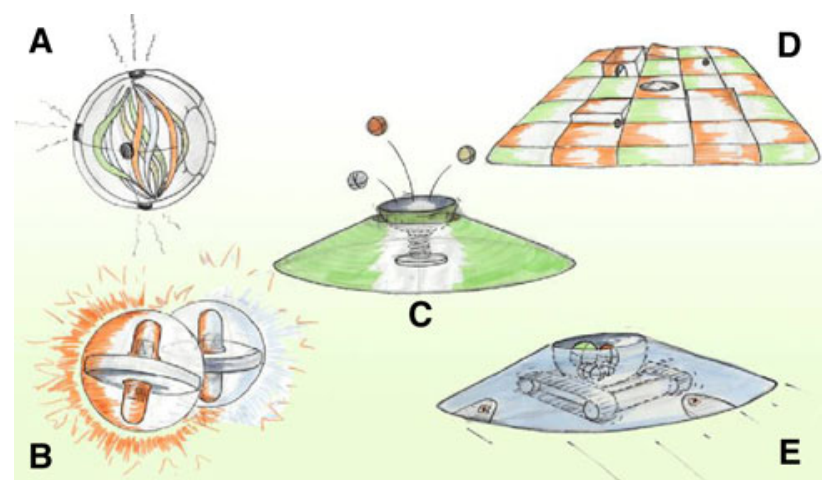

Fig. 3 Five different game concepts: Magnet Marbles (a), Color Marbles (b), Timer Hole (c), Obstacle Surface (d), and Moving Hole (e)
Magnet Marbles: The concept of adding magnets to the marble game focuses on the loss of control and the possible advantages and disadvantages that come with the use of magnets. The concept consists of flexible shells that can be pulled over a marble and contain a set of six small magnets. By turning the shell inside out, the marble can get a positive or negative charge.

Color Marbles: In the concept of color marbles, light is implemented in the marbles of the game. The marbles can detect whether they are hit by other marbles. Changing of the color is triggered by getting hit by another marble. This can be extended by changing the color when having physical contact with the human body (finger).

Timer Hole: The timer hole adds the aspects of time and surprise, creating a faster game that should increase the anxiety level of players. Measuring the time between the first and the second marble that hit the hole, creates a time limit of how fast the next marble has to be in the hole. When the marble is too late in the hole, the hole shoots the marbles that are in it, back out.

Obstacle Surface: The obstacle surface consists of several tiles with an integrated marble hole. The tiles can be manipulated in altitude by the marbles. By sensing whether a marble moves over a tile, a tile takes on a different position. In this way, the next shot can become more difficult or easier for the opponent. By random functions of the moving of the tiles, the game can be surprising yet controllable.

Moving Hole: The Moving Hole makes use of its surroundings by detecting and avoiding obstacles. The player not only controls his marbles but also the hole. The time between two marbles that hit the hole is converted into movement so that fast play is stimulated. Direction of movement is determined by the direction of the marble that hits the hole. This way the player can score a marble and position the hole for the next shot.

\subsection{The Marbowl game}

The choice for the final concept is based on the requirements that resulted from Sects. 4, 5, and 6.1 (see Table 3). These requirements are based upon the gameflow theory and the validation done in Sect. 4.2, with a focus on the physical interaction of the game that is further developed in Sect. 5 of the study. By analyzing and rating each concept on the different requirements, we could give an indication of the concepts that are likely to have the best gameflow and highest fun experience. The highest scoring concept was developed into a working prototype to test the actual fun experience among the target group.

Results of our analysis indicated that the moving hole concept matched the requirements best. The stakes within 
Table 3 Requirements for the improved game and results of the five different concepts: Magnet Marbles (MM), Color Marbles (CM), Timer Hole (TH), Obstacle Surface (OS), and Moving Hole (MH)

\begin{tabular}{|c|c|c|c|c|c|}
\hline Requirements & & & & & $\frac{\mathrm{MH}}{\sqrt{63}}$ \\
\hline $\begin{array}{l}\text { The stakes of the game should remain "flexible" or have to be able to be determined } \\
\text { by the players }\end{array}$ & 5 & 4 & 5 & 5 & 5 \\
\hline The game should integrate the option to play against opponents & 5 & 5 & 5 & 5 & 5 \\
\hline Additions to the game, surface, and marbles should be portable & 4 & 5 & 4 & 2 & 4 \\
\hline Players should be able to develop skills through playing with the new addition & 5 & 5 & 4 & 5 & 5 \\
\hline $\begin{array}{l}\text { The aspect of collecting marbles should remain: The diversity of marbles should } \\
\text { remain and should be visible }\end{array}$ & 5 & 3 & 5 & 5 & 5 \\
\hline The design should stimulate social interaction between players & 5 & 5 & 3 & 5 & 5 \\
\hline $\begin{array}{l}\text { Direct feedback of shooting the marble with a finger should remain (using hard } \\
\text { materials for possible marble designs, no soft addition for fingers) }\end{array}$ & 2 & 4 & 5 & 5 & 5 \\
\hline $\begin{array}{l}\text { The design should not only aid the players in their player skills but create a balance } \\
\text { between aiding and making the game more difficult }\end{array}$ & 5 & 5 & 3 & 5 & 5 \\
\hline $\begin{array}{l}\text { The design should be an added element to the game that increases the level of } \\
\text { difficulty and loss of control without drastically changing the physical interaction } \\
\text { with the marbles }\end{array}$ & 4 & 3 & 5 & 5 & 5 \\
\hline The difficulty of the game should be controllable by the players & 2 & 5 & 2 & 3 & 4 \\
\hline The design should stimulate the feeling of having control & 3 & 5 & 3 & 3 & 4 \\
\hline Interaction with the marbles should be designed for shooting with fingers & 5 & 5 & 5 & 5 & 5 \\
\hline The design should be feasible regarding playability, fabrication, and production & 4 & 4 & 3 & 3 & 4 \\
\hline Total score & 54 & 58 & 52 & 56 & 61 \\
\hline
\end{tabular}

Where $1=$ does not meet the requirements at all and $5=$ fully meets the requirements

this game variant remain the same, as the collecting and trading of marbles. Where the moving hole as the obstacle surface both look at using the surface to change the game, the moving hole focuses more on the environment itself and uses the playground and players' creativity instead of a designed surface. Developing player skills is addressed by added game elements like time, surroundings, and direction of shooting marbles, which have to be considered during the game. However, players can also choose to disregard using tactics.

Direct feedback with the marble and having the feeling of control remains. Players can lose or gain control depending on their own and the opponents' skill and the chosen game surface or playground.
The only areas that this concept does not fully cover are; setting the difficulty, which could be added to the final design; the loss of control, which could be a setback for some players; and the playability slightly differs from the regular variant where the hole is normally equally leveled with the ground.

A working prototype entitled Marbowl was created (see Fig. 4). By means of caterpillar tracks, the body is able to move over different surfaces and small obstacles. The caterpillar tracks are powered by two DC motors that are controlled by an Arduino [19] microcontroller.

The microcontroller senses by means of a force sensible resistor whether a marble falls into the hole and starts counting. When a second marble is shot into the hole, the
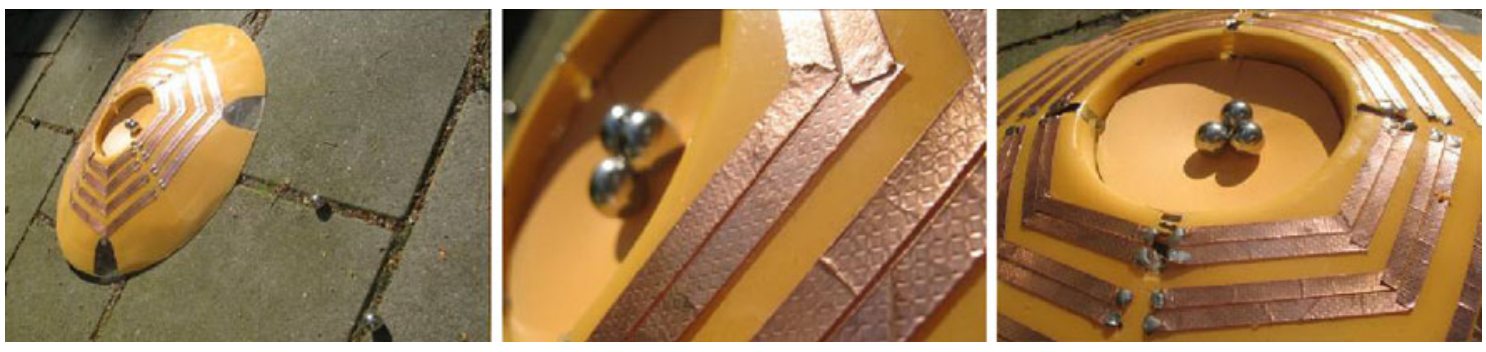

Fig. 4 The Marbowl prototype 
counter stops and converts the time into seconds of movement.

To give direction to the movement, the microcontroller measures where the marble is coming from by means of contacts on the surface of Marbowl that are enabled when a marble rolls over the body. The derived signal makes the caterpillar tracks turn into the opposite direction, so the players can steer the target toward other marbles or objects.

To avoid obstacles Marbowl is equipped with light sensors (see Fig. 5) that make it possible to detect nearby objects. When the sensor drops below a certain value, which happens when it comes close to an object, a signal is given to move the device away from the object in a random direction. By making this a random movement, the element of surprise is added and players can either benefit or be given a disadvantage by it.

To focus the results on the developed success factors, we decided to keep the design as close to the original coneshaped marble holes as possible. However, because of implemented electronics, the size of the hole increased. To eliminate size difference during the following field study, another body was vacuum formed without the electronics and ability to move.

\section{Evaluating fun experience (Phase 4)}

To test the differences in experienced fun between the original and improved game, a field study was performed with the same 24 children as in Sect. 5.1. Two separate playgrounds were created in the schoolyard, one with the original game and the other with the Marbowl prototype.
The two variants were counterbalanced to prevent order effect. Each playground was out of sight from the other to prevent the children from distracting each other.

The class was divided into five groups. Every $15 \mathrm{~min}$, two groups simultaneously tested one of the two game variants (see Fig. 6). After testing, each variant players rated the variant on ten different topics (see Table 4) on a short evaluation form.

These topics, based on the gameflow areas and previous conclusions, were rated by means of a smiley-o-meter [22, 23]. After each smiley, children were given the option to indicate why they chose that smiley. Where the overall level of fun experience is indicated by the smiley-o-meter, new ideas and remarks on the improved game were elicited in the open answers.

After finishing the questionnaire, the groups switched playgrounds and played the other game variant for another $15 \mathrm{~min}$. Then, the same questionnaire was again used to evaluate the other variant. This process was repeated until all groups played and evaluated both variants.

\subsection{Field study results}

The overall results of the gathered data can be divided into the areas that we asked the children to rate. Looking at the results (see Fig. 7), significant differences were found in the areas of overall fun experience, the level of play, the challenge, and the amount of concentration needed. Below, the results of each area are explained in more detail.

Fun Experience: The overall fun experience of Marbowl was significantly rated higher than the original game variant. The majority of the children indicated that the
Fig. 5 Overview of the different parts of the Marbowl, with in the background the electronics implemented in the Marbowl prototype

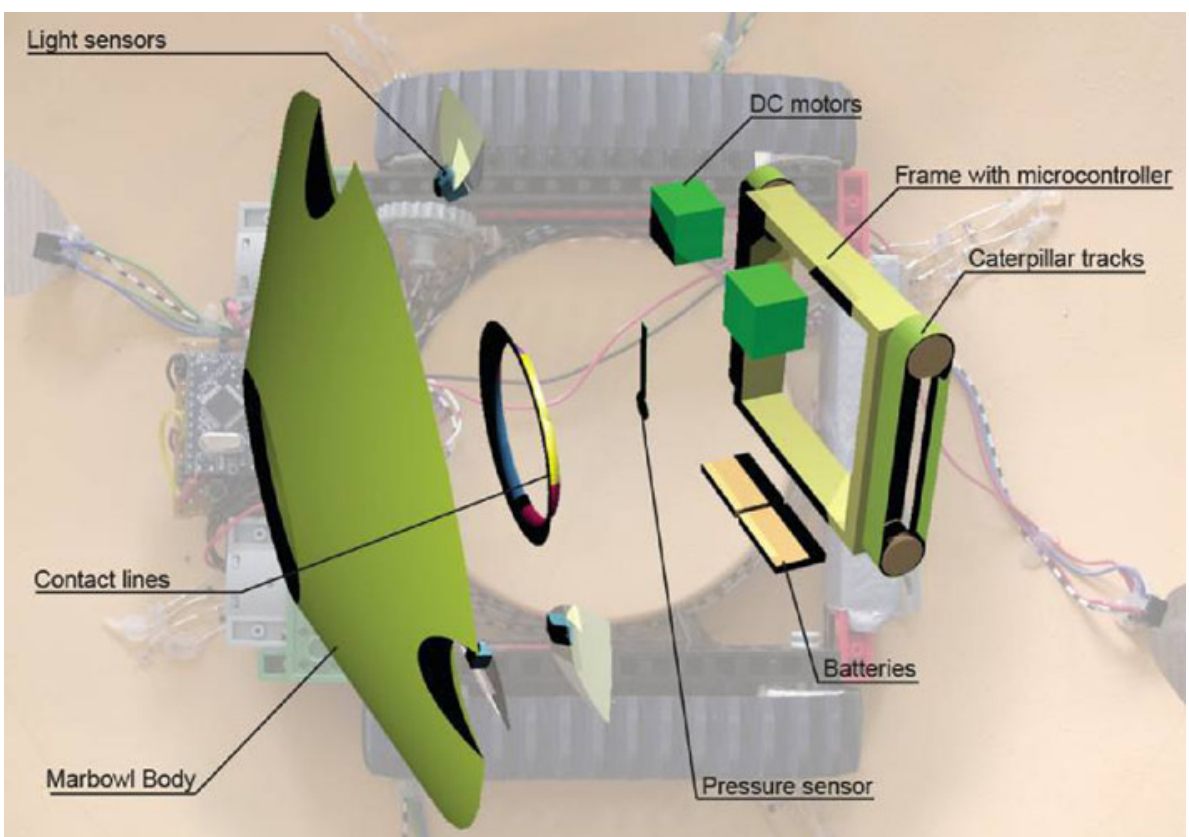



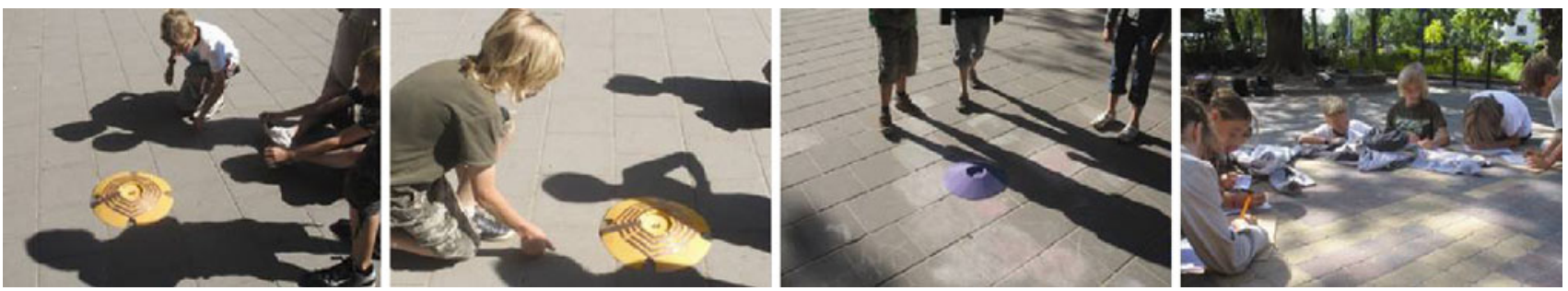

Fig. 6 Children playing and evaluating the two game variants

movement of the marble hole was experienced as something new, positive, and funny. Results show us that these children gave the new concept the maximum positive rating, where the original game had a more average rating.

Level of play: Children rated their own skill in playing the game significantly higher while playing with Marbowl. Although the qualitative responses did not give any explanations for the higher score for Marbowl.

Skill Development: The level in which a player can develop their skills was rated in both variants as "good", though, children indicated that they were not skillful at shooting marbles and did not see themselves becoming better at the game in the near-future. However, during our observations, we already noticed children getting more accurate in steering Marbowl and successfully steering and moving it in the direction of other marbles.

Difficulty: In both variants, the children indicated that it was difficult to shoot marbles in the hole and win the game. Some children indicated that the marble holes were too big and shooting marbles was more difficult than expected, while other children indicated that by steering Marbowl it was easier to get the marbles closer to the hole.

Challenge: Ratings of whether the children found the variants challenging indicated that Marbowl was experienced as significantly more challenging. The main reason given for the challenge increase in the Marbowl game was the newly integrated functionally.

Concentration: The level of concentration of the children was higher while playing with Marbowl compared with the regular game variant. According to the children, the movement of the target increased the amount of focus that was needed to win the game.

Control: The feeling of having control over the game was higher during the Marbowl variant. Children indicated that the amount of control was strongly determined by the surface and the movement of the hole. The feeling of control decreased in both variants by the tiles and by the unequal surface so that marbles often headed different directions than intended.

Table 4 Ten topics, their definition, and the questions which were rated by the children during the field test

\begin{tabular}{|c|c|c|}
\hline Topics & Definition & Question \\
\hline 1. Fun experience & $\begin{array}{l}\text { Players should experience an appropriate amount of fun while } \\
\text { playing the game }\end{array}$ & How much fun did I have while playing the game? \\
\hline 2. Level of play & $\begin{array}{l}\text { The game should provide players with a sense of being able to } \\
\text { play the game on their personal skill level }\end{array}$ & How good did I play the game? \\
\hline 3. Skill development & The game should support the development of players' skill & How good can I improve my game? \\
\hline 4. Difficulty & $\begin{array}{l}\text { The game should provide an appropriate amount of difficulty to } \\
\text { complete the game }\end{array}$ & How difficult was it to win the game? \\
\hline 5. Challenge & The game should be sufficiently challenging & How challenging was the game? \\
\hline 6. Concentration & $\begin{array}{l}\text { The game should require an appropriate amount of } \\
\text { concentration needed }\end{array}$ & How was the level of concentration needed? \\
\hline 7. Control & $\begin{array}{l}\text { The game should integrate direct physical control and direct } \\
\text { feedback on actions }\end{array}$ & How was the amount of control over the game? \\
\hline 8. Surface & $\begin{array}{l}\text { The game leaves room for individual manipulation of its } \\
\text { environment }\end{array}$ & How did the surface influence my game? \\
\hline 9. Opponent & $\begin{array}{l}\text { The game should support social interaction between players } \\
\text { and leave room for competition and cooperation }\end{array}$ & How did the opponent influence my game? \\
\hline 10. Desire to play & Players should have the desire to play the game again & How much would I like to play the game again? \\
\hline
\end{tabular}


Fig. 7 Overview of the differences between the Marbowl and original marble game. Means and boundaries of rated topics with a $75 \%$

Confidence Interval between the differences

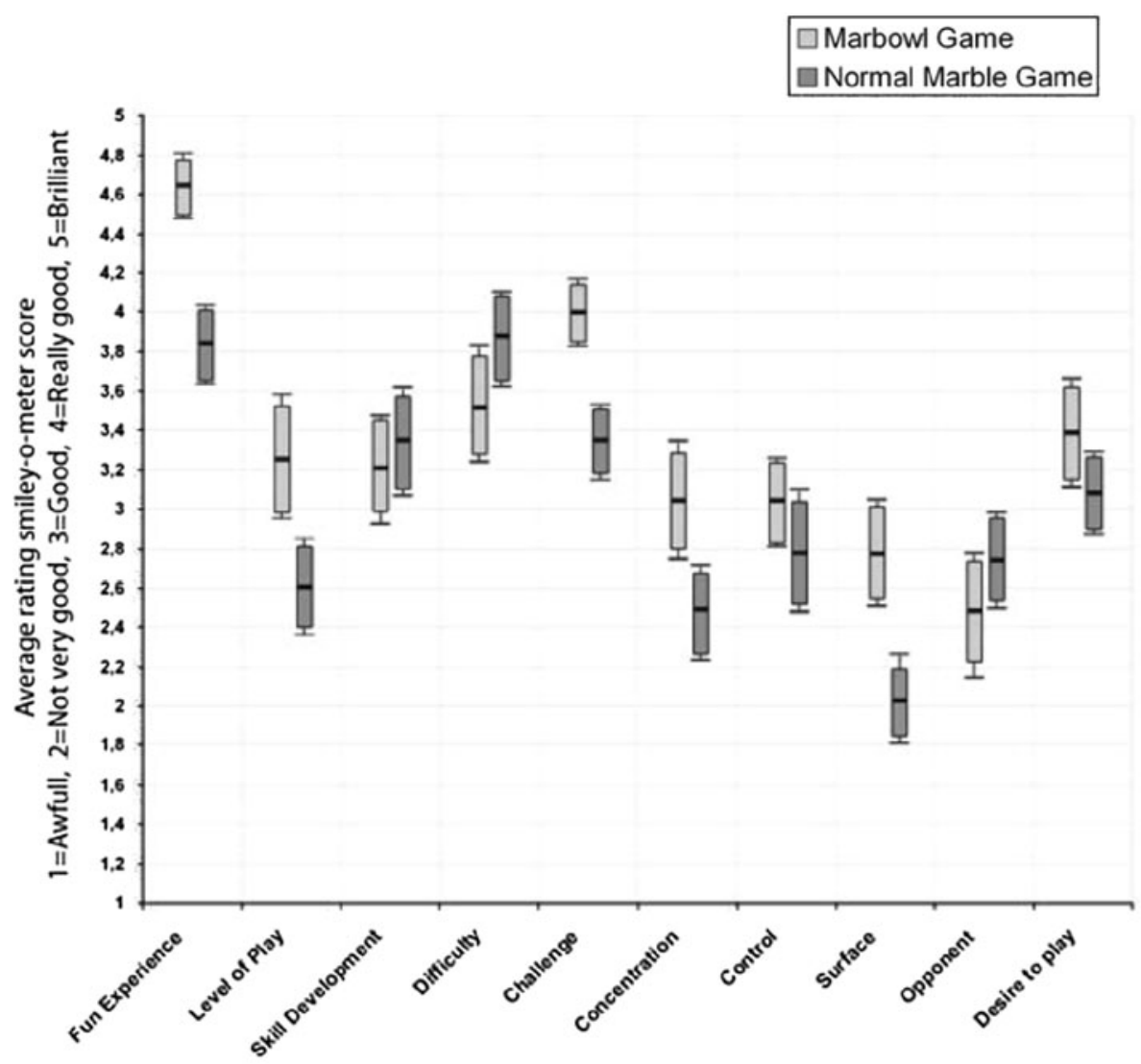

10 Topics based on the requirements and gameflow areas
Surface: The playability of the surface was rated as bad or even terrible by the majority of the respondents. This was caused by the tiles on the schoolyard and the small slots between them that obstructed the marbles. Children indicated that, because of the mobility of Marbowl, they could "manipulate" the surface and therefore rated the playability of the surface significantly higher for that variant.

Opponent: The influence of the opponent on the game was rated mostly to be "good". Answers given showed that during the original game players prevented their opponent to score more than with Marbowl. From our own observations, we saw that during the original game players focused more on the opponent, while with Marbowl the focus was more on the moving hole.

Desire to Play: When asked to what extent children would like to play the game again, ratings were above average. Also, in this area, Marbowl was rated slightly higher.

\subsection{Gameflow}

The overall results indicate that Marbowl was experienced as more positively and fun compared with the regular marble game. When relating this to the different gameflow areas, we see that several aspects played an important role.
Because of the development of existing game factors, gameflow areas like concentration, challenge, and control were improved, experienced, and rated more positively than the original game.

The gameflow area of clear goals was not addressed by the development of the prototype, for the results of the validation in Sect. 4.2 already showed us that participants indicated this area as somewhat obsolete for the game of shooting marbles.

Feedback is a gameflow area that was investigated in the second phase of this study where the decision was made not to change the interaction with the marbles. However, the visual feedback that players receive coming from the direct coupling of time and movement, the direction of the marble and the direction of movement, were rated as positive as well. Players' main focus lay on the movement and hitting the hole while the target was moving. They did not relate the time between hits to the time of movement. This could be made more clear by adding feedback in a future design iteration.

Looking at the gameflow area of player skills, we see a slightly negative curve in the quantitative results. Even though the qualitative answers given by the children indicated that both variations were experienced similarly when it comes to getting better at the game. 
Although the smiley-o-meter did not cover the gameflow area of social interaction fully, we got a good indication of how children experienced the opponent during both variants through the qualitative answers and observations made during the test. The open questions indicated that children find the opponent one of the most important success factors of a game and often mentioned new collaborative game possibilities for the Marbowl.

Although we did not measure the level of immersion while playing both game variants, during our observations, it seemed that in the original variant children were more occupied with each other, where with Marbowl they seemed more occupied by the game itself.

\section{Discussion}

Looking at the results and approach of this study, we see that elaborating existing game elements can benefit the experienced fun of players. Existing success factors of the marble game like the surface and physical interaction were investigated and extended. This not only resulted in an exciting new marble game but can also be seen as an example of how to increase the experienced fun of an existing game by applying the gameflow theory on a physical game. Not only can such an approach be preferred to build on successful game formats and bring an existing game to a higher level, it can lead to new insights and create opportunities for the development of new games as well.

Until now, the gameflow theory was only used within the area of digital gaming, while we applied it to evaluate a physical game. The outcome of our study implies that our approach can be usable and useful for the development of physical games. The significant differences, such as the experienced fun and the amount of challenge, can be interpreted as a validation of the improvements made which are based upon the analysis of the game through the criteria set for each gameflow area. However, like Sweetser and Wyeth [28] already mentioned in their analysis, some criteria are better suited for certain types of games. Within the shooting marble game, we identified such criteria early in our study (Sect. 4) by validating the game with experts. Gameflow areas like Clear Goals and Feedback were then adjusted to the evaluated game. Although improving such areas may lead to a higher fun experience, improving gameflow areas that are more relevant to the game is likely to have a bigger impact. This was indicated by the target group (Sect. 5), who identified the areas that have the biggest influence on the experienced fun. The evaluation of the improvements made within these areas, showed that this impact can make a significant difference in comparison with the original game. Users for example indicated that the concentration needed during the Marbowl game increased by the movement of Marbowl and that it thereby also grabbed their attention and maintained their focus longer than with the original game. Users also rated the challenge higher which implied that Marbowl provided different levels of challenge by for example only focusing on hitting a moving target or by actually steering Marbowl toward other marbles. Without removing existing game opportunities, new possibilities are created for open-ended play. While it is still possible to choose the environment, to use obstacles within that environment and to choose any opponent a player likes, the technological advancements create new opportunities to manipulate output. The translation of the existing input (shooting a marble) elicits certain behaviors of Marbowl that can potentially realize collaborative types of play within the game. This is supported by the suggestions made by the children during the final field test, where they mentioned opportunities for different types of collaborative play such as steering Marbowl toward a co-player's marble and using team efforts to move Marbowl to certain locations. Together with other factors, this indicated why Marbowl was experienced as more fun than the original game and thereby indicated that the use of the gameflow theory can be beneficial for the development of the shooting marble game.

Although our approach takes a step in the right direction and the results indicate the potential and opportunities for applying the gameflow theory on other physical games, several limitations during our study have to be considered in future research. To eliminate the effect of positive surprise and first-time enthusiasm that often bias elicited opinions of participants, in particular with children, longitudinal studies with the Marbowl game have to be performed. Furthermore, it can be discussed whether using the same respondents in multiple phases of the study was beneficial or not. Like mentioned in Sect. 5.1, the attuning of respondents to the topic helped us to gather data more efficiently and effectively. However, using multiple classes with children who were not involved during any other phase of the study may have lead to a higher validity of the gathered data. We believe that, regarding the tasks given to the respondents, using the same respondents did benefit the course of our study. Taking these limitations into consideration, future analysis and developments of physical games for children can be supported by the presented approach.

The approach suggests opportunities in particular for the field of tangible interaction. One of the features of tangible interaction is that you have multiple interactive artifacts that are related to a digital system. Somehow, when you start designing from scratch in a user-centered design process, it is hard to end up with a tangible user interface, since this is a solution space and hard to set as a 
requirement. But we see a trend that tangible interaction more and more will start from existing physical artifacts, as stated in [12], instead of inventing new ones. In case you want to start from existing activities and artifacts, our elaboration method can transform existing artifacts into tangible user interfaces while adding meaning. The presented approach shows future developers and researchers several steps that can be taken to achieve this transformation, using the criteria set within each gameflow area to first identify and specify the most important game factors in order to improve them.

\section{Conclusions}

This paper studied the game factors which make the game of shooting marbles popular. We used the gameflow model and evaluated the outcomes with both the experts and the marble playing target group (children of 9-12 years old). Results showed that the biggest influences on the fun experience of the game were the Stakes, Opponent, Surface, and Physical Interaction of the game. Physical Interaction was chosen for further development based on the preferences of the target group. This area also addressed the different success factors and offered multiple design-opportunities for open-ended play and stimulating social interaction.

Four developed concepts of physical interaction within the marble game were evaluated in a field study which resulted into the following three conclusions. First, the direct contact with the marble should remain for direct physical feedback and a better control over the marble. Secondly, aiding the players by making it easier to shoot a marble is experienced as negative by the children. Finally, children experienced an increase in difficulty by added elements as something positive.

Based on these conclusions, five concepts were developed. By the formulated requirements, the Moving Hole concept was selected as the best fit and was developed into a working prototype entitled Marbowl. The results of the field study show that playing with Marbowl increased the experienced fun compared with the original game. In addition, we showed that using an existing physical game and by redesigning one of the success factors we created new opportunities for open-ended play and social interaction.

Acknowledgments We thank all the children, teachers, and board of the primary school "De Floralaan" and all the students for their participation and support during the field studies and co-design sessions. We also thank Panos Markopoulos and Iris Soute for their input regarding the setup of our study and /d.search-labs for their support with the building of the prototype.
Open Access This article is distributed under the terms of the Creative Commons Attribution Noncommercial License which permits any noncommercial use, distribution, and reproduction in any medium, provided the original author(s) and source are credited.

\section{References}

1. Acuff DS, Reiher RH (1997) What kids buy and why, the psychology of marketing to kids. The Free Press, New York

2. Antle AN (2007) The CTI framework: informing the design of tangible systems for children. In: Proceedings of the first international conference on tangible and embedded interaction (TEI), Los Angeles, USA, pp 195-202

3. Bakker S, Vorstenbosch D, van den Hoven E, Hollemans G, Bergman T (2007) Tangible interaction in tabletop games: studying iconic and symbolic play pieces. In: proceedings of the international conference on Advances in Computer Entertainment technology (ACE), Salzburg, Austria, pp 163-170

4. Bean A, Siddiqi S, Chowdhury A, Whited B, Shaer O, Jacob RJK (2008) Marble track audio manipulator (MTAM): a tangible user interface for music composition. In: Proceedings of the second international conference on tangible and embedded interaction (TEI), Bonn, Germany, pp 27-30

5. Beckhaus S, Schröder-Kroll R, Berghoff M (2008) Back to the sandbox-playful interaction with granules landscape. In: Proceedings of the second international conference on tangible and embedded interaction (TEI), Bonn, Germany, pp 141-144

6. Bekker MM, van den Hoven E, Peters P, Hemmink B (2007) Stimulating children's physical play through interactive games: two exploratory case studies. In: 6th international conference on interaction design and children (IDC), Aalborg, Denmark, pp 163-164

7. Bekker T, Sturm J, Eggen B (2009) Designing playful interaction to stimulate social and physical play, personal and ubiquitous computing, online first. doi:10.1007/s00779-009-0264-1

8. Bruckman A, Bandlow A (2003) HCI for kids. In: Jacko J, Sears A (eds) Human-computer interaction handbook. Lawrence Erlbaum, Hillsdale, pp 428-440

9. Csikszentmihalyi M (1990) Flow: the psychology of optimal experience. In: Information design journal, vol 16, issue 1. Harper Perennial, New York, pp 75-77

10. Druin A (1999) Cooperative inquiry: developing new technologies for children with children. In Proceedings of the SIGCHI conference on Human factors in computing systems: the $\mathrm{CHI}$ is the limit (CHI), Pittsburgh, USA, pp 592-599

11. Flippo Wikipedia page. In: http://nl.wikipedia.org/wiki/Flippo Last accessed: Mar 142010

12. van den Hoven E, Frens J, Aliakseyeu D, Martens J-B, Overbeeke K, Peters P (2007) Design research \& tangible interaction. In proceedings of tangible and embedded interaction (TEI), Baton Rouge, USA, pp 109-116

13. Ishii H, Ullmer B (1997) Tangible bits: towards seamless interfaces between people, bits and atoms. In: Proceedings of the ACM conference on human factors in computing systems (CHI), Atlanta, USA, pp 234-241

14. Jensen JJ, Skov MB (2005) A review of research methods in children's technology design. In: Proceedings of the 4th international conference on interaction design and children (IDC), Boulder, USA, pp 80-87

15. Mahmud AA, Mubin O, Octavia JR, Shahid S, Yeo LC, Markopoulos P, Martens J-B (2007) aMAZEd: designing an affective social game for children. In: Proceedings of the 6th international conference on Interaction design and children, (IDC) Aalborg, Denmark, pp 53-56 
16. Markopoulos P, Bekker MM (2003) Interaction design and children. Interact Comput 15(2):141-149

17. Markopoulos P, Soute I (2007) Head up games: the games of the future will look more like the games of the past. In: Baranauskas C, Palanque P, Abascal J, Barbosa SDJ (eds) Human-computer interaction-INTERACT 2007, volume 4663/2008. Springer, Berlin, pp 404-407

18. Mazalek A, van den Hoven E (2009) Framing tangible interaction frameworks. In: "Tangible interaction for design" special issue of AIEDAM, Spring 2009, vol. 23, pp 225-235

19. Mellis DM (2006) Arduino microcontroller. In: http://www. arduino.cc, Last accessed: Mar 312010

20. Pardo S, Vetere F, Howard S (2005) Broadening stakeholder involvement in UCD: designers' perspective on child-centered design. In: Proceedings of the 17th Australia conference on computer-human interaction: citizens online: considerations for today and the future (OZCHI), Canberra, Australia, pp 1-9

21. Price S, Rogers Y, Scaife M, Stanton D, Neale H (2003) Using 'tangibles' to promote novel forms of playful learning. Interact Comput 15:169-185

22. Read J (2008) Validating the Fun toolkit: an instrument for measuring children's opinions of technology. Cogn Technol Work 10(2):119-128

23. Read J, MacFarlane S, Casey C (2002) Endurability, engagement and expectations: measuring children's fun. In: Proceedings of the international workshop interaction design and children, Eindhoven, The Netherlands, pp 189-198

24. Seitinger S, Sylvan E, Popovic M, Zuckerman O, Zuckerman O (2006) A new playground experience: going digital? In: Extended abstracts on human factors in computing systems (CHI), Montreal, Quebec, Canada, pp 303-308
25. Smartus by Lappset homepage, In: http://www.smartus.com/, Last accessed: Mar 30, 2010

26. Soute I (2007) HUGS: head-up games. In: Proceedings of the 6th international conference on Interaction design and children (IDC), Aalborg, Denmark, pp 205-208

27. Swanborn PG (1982) Schaaltechnieken: Theorie en praktijk van acht eenvoudige procedures. Uitgeverij Boom, Amsterdam

28. Sweetser P, Wyeth P (2005) GameFlow: a model for evaluating player enjoyment in games. In: Computers in entertainment, vol. 3, no. 3, pp 3-27

29. Swinxs homepage, Last updated: Mar 19 2010. Available via: http://www.swinxs.com

30. Trochim WMK (2006) Likert scaling. In: Web center for social research methods. Available via: http://www.socialresearch methods.net/kb/scallik.php. Last accessed: Dec 152008

31. Verhaegh J, Soute I, Kessels A, Markopoulos P (2006) On the design of Camelot, an outdoor game for children. In: Proceedings of the 5th international conference on interaction design and children (IDC), Tampere, Finland, pp 9-16

32. Xie L, Antle AN, Motamedi N (2008) Are tangibles more fun? comparing children's enjoyment and engagement using physical, graphical and tangible user interfaces. In: Proceedings of the second international conference on tangible and embedded interaction (TEI), Bonn, Germany, pp 191-198

33. Yannakakis GN, Hallam J, Lund HH (2006) Comparative fun analysis in the innovative playware game platform. In: Proceedings of the 1st world conference on fun and games, Preston, England, pp 1-8 